\title{
Research on the Application of Computer Software Technology in the Era of Big Data
}

\author{
Chen Shuang ${ }^{1}$, Luo Qiqiang ${ }^{2}$ \\ ${ }^{1}$ Jiangxi Tellhow Animation Vocational College, Nanchang, China \\ ${ }^{2}$ Nanchang Institute of Science and Technology, Nanchang, China
}

Keywords: the era of big data; computer software technology; application research

\begin{abstract}
With the comprehensive development of China's social economy, the development of science and technology has ushered in a new stage, and the innovation and development of computer technology is the most important evidence. At present, computer information technology has entered people's life and becomes a necessary part, bringing great assistance for people's work and study. In the era of big data, the application of computer software technology is more extensive and the development prospect is more prosperous. Therefore, it is significant to improve computer software technology, which can enhance the overall operation speed of China's economy to a great extent. Based on this, this paper explores and analyzes the actual application of computer software technology and provides personal opinions.
\end{abstract}

Nowadays, the application of computer information technology greatly changes people's traditional lifestyle. In fierce market competition, to occupy a position in the market, enterprises shall start with computer software technology to efficiently save manpower and material resources, so that the operation of enterprises can be more scientific and systematical, which is beneficial to the development of enterprises. With the advent of network era, China's IT industry becomes stronger. For enterprises, data produced in operation and management is the most core asset of enterprises. In the era of big data, many enterprises are faced with new challenges. At present, the era of big data brings more possibilities for the development of computer software processing technology. At the same time, its development promotes the overall development of China's enterprises.

\section{The Application of Computer Software Technology in the Era of Big Data}

With the improving Chinese science and technology, the development of computer software technology enters a personalized stage, where it has been widely applied in all walks of life and ideal results have been obtained, so that the competition advantages of many industries and enterprises are improved, and people are encouraged to strengthen their exploration of computer software technology. In the era of big data, the integration of big data and computer technology has become the inevitable trend of times. At present, big data mainly refers to data set captured and managed by common software with certain time and scope. In order to ensure the quality of effectively management of big data, it is necessary to ensure that relevant personnel shall be equipped with excellent professional quality, acute insight and executive force, which is crucial. In the era of big data, the rapid development of computer software technology brings great convenience for people's life and great development space for various fields in China.

\section{The Application Types of Computer Software Technology in the Era of Big Data}

For the era of big data, only by finding the law in the development of the times can the enterprise remain invincible. In this era, the needs of users have also changed. Therefore, when designing the computer software technology, it is necessary to design data characteristics according to actual requirements of users. The key technologies of computer information processing mainly include 
three aspects.

\subsection{Virtualization technology}

In terms of computer software technology, virtualization technology is most important. It is to carry out configuration and management according to virtual resources to realize the optimization of big data resources, so as to ensure the overall operation quality and efficiency of enterprises, as well as flexible operation [1].

\subsection{Cloud storage technology}

At this stage, cloud storage technology occupies a very important position in the field of computer software development in China. Cloud storage is composed of multiple storage units. In actual work, the operation of cloud storage technology requires multiple technologies to support. In the current era of big data, people have more and more channels to obtain information, and the speed of information transmission is also faster and faster. The massive information reserves fully meet the diversified needs of people for different information. Under the background of this era, the emergence of cloud storage technology has largely affected people's daily life and work. When the search and calculation of massive information is completed, the information needs of users have been effectively satisfied. This technology has also become an indispensable important link in the process of information data calculation in China, and plays a very important role in the operation of computer software systems.

\subsection{Information security technology}

With the continuous development of computer information technology in China, the form of information transmission has become more diversified. At the same time, the security problem of information transmission has gradually attracted people's attention. The information transmission is often subject to some external factors, which leads to that the effect of information transfer is not ideal. In the era of big data, there is a certain correlation between the transmission of various information, which often poses a certain threat to the security of information. To effectively prevent this risk, it is necessary to conduct in-depth development of information security technology, apply it to the computer information transmission, and adjust the entire data management system, so that the security of the data cluster is effectively improved [2]. In the future development of the industry, in order to ensure the security of data information transmission, it is necessary to continuously conduct in-depth research on information security technology. Although the history of the application of big data technology in China is not long, it has gained a broad mass base. In the future development, China's computer software development technology will face more challenges, so each industry should explore and analyze the actual situation of development, so as to formulate the plan that best meets the development of the enterprise. The computer software technology can only serve the purpose of assisting the development and construction of the enterprise. The actual operation and development of the enterprise depends on the operation mode of the enterprise itself. When processing information data, it is very important to match the overall operation mode of the current enterprise. Only in this way can the overall quality of the enterprise operation be guaranteed [3]. The application of computer software technology in the era of big data can efficiently improve the authenticity and effectiveness of data.

\section{Analysis on the Application of Computer Software Technology in the Era of Big Data}

At present, the development of computer software technology in China has ushered in a new stage and improves greatly in technology, which is directly related to continuously efforts of relevant researchers in this industry. The development of computer software technology in the future shall be conducted in three aspects.

\subsection{Information communication}

With the continuous improvement of China's science and technology, the development of related 
prediction software is also constantly improving. The use of IBMSPSS predictive analysis software can greatly reduce the loss of customers, which helps the smooth operation and development of the enterprise. For the communication industry, in daily work, it is necessary to sort out the relevant information of the customer. This requires reasonable application of the predictive analysis software to analyze the future development forms of some customers, and then send these materials to the top management personnel, in this way, the economic efficiency and overall operational quality will be a relatively stable state.

\subsection{The application in enterprise operation}

For enterprises, in the operation, they often encounter information verification and sorting. The adoption of enterprise operation management software can effectively complete customer data acquisition and risk analysis, and at the same time, it can also analyze employee turnover at the current stage. In the era of big data, the application scope of computer software technology is expanding, bringing people a more diversified and faster experience. The development of data is divided into five parts [4]. First of all, sampling. The so-called sampling is to randomly select the products during the production process. The selected samples are often representative. At the same time, when sampling, it is also necessary to pay attention to the accurate setting of the sample capacity, which affects greatly the operability of samples; secondly, development. The birth of any product and technology must be developed first. The exploration and research can be carried out to realize the development and utilization of products, and the development of data information can further deepen people's understanding of data information. The development of data information often involves many aspects and external factors, which requires personnel in technology development to be equipped with higher professional quality [5]. The technological development involves various procedures, including data input, data merge and data selection and so on; thirdly, modification. People can modify the data by creating and selecting, which is very necessary. The modification often involves the conversion between variables and the update of the product code, etc., and the sharing operation by virtue of the corresponding data; fourthly, model. The use of the model is mainly to make the final forecasting result more accurate, which plays a very important role in the operation of the enterprise, and it is also the key to promote the overall operation and development of the enterprise; fifthly, evaluation. Evaluation technology is a new technology generated after comparative analysis with model technology. In data mining, relevant technicians should continuously innovate the data development model, which is very critical. The accuracy of data is the basic premise of data innovation. The tools for visualization at this stage have been widely used and have been widely welcomed among users. With the help of visualization tools, users can find the information they need in a short time, which can be shown in graphics, so that the relevant staff can have a clear understanding of the running status according to the dynamic situation of the data [6].

\subsection{The application in information-based teaching}

For a country, the cultivation of talent is most important, and the prosperous development of education cause enhances the quality and efficiency of talent cultivation. In the new era, China's education cause is faced with new challenges, and traditional education and teaching concept cannot meet the requirements of the times. Thus, it is necessary for education field to be actively integrated with computer technology [7]. At present, information-based teaching is widely applied in China's education and teaching, greatly enhances students' interests in learning, and promotes the overall development of education industry. Compared with the traditional education mode, information-based teaching technology will not be restricted by time or place. As long as students want to learn related knowledge, they can use the network to study. After long-term practice, the online teaching method can effectively improve students' self-learning ability, and greatly improve students' enthusiasm for learning. When students are interested in learning, the improvement of academic performance becomes very easy [8]. Especially when teachers are teaching geometric knowledge, the traditional teaching of geometric knowledge is often boring, and students are hard to be interested in the process of learning. With the extensive application of computer software 
technology, the original abstract geometric knowledge becomes visualized and closer to life. It is also easier for students to understand geometric knowledge points. Computer software can clearly present the changes in the graphics to students, which is much better than the traditional narration by teachers or the props presentation. In addition, computer software technology also exert ideal results in the Chinese classroom teaching [9]. For instance, when teachers explain the Guilin Landscape, the traditional teaching method can only be realized by the oral narration of teacher and the text for students to experience the magnificent landscape of Guilin. However, when computer information technology is applied to the teaching activities of Chinese class, students can have a more comprehensive and specific understanding of the landscape of Guilin through video or slide show, which also greatly enhances students' interests in learning Chinese. Teachers can also use computer technology for the preview of the texts. Students can learn about the creative background and creative intentions of the writers, so that students' language learning efficiency and quality can be improved. After students have a preliminary understanding of the texts, it will be easier to carry out targeted study. In addition, teachers can prepare some interesting micro videos related to the important knowledge points of this lesson in teaching each subject, which will greatly improve students' self-learning ability [10].

\section{Conclusion}

At present, the speed of science and technology development in China is accelerating. With the advent of big data era, the scope of application of computer software technology is also expanding, ideal in data analysis, data collection and data storage. Under the current environment, the effective application of computer software technology has greatly promoted the overall development of the enterprise and improved the overall quality and efficiency of the enterprise operation. In addition, computer technology is widely applied in the field of education in China, which effectively enhances students' interests in learning, and greatly promotes the talent cultivation in China. People have applied computer software technology to various fields in China. With the help of computer software technology, many industries and enterprises have gained more broad space for development. People are strongly dependent on computer technology. Whether it is life or work and study, it is inseparable from the support of computer technology. It is precisely because of the background of this era, that the speed of computer technology is accelerating and the diverse needs of different users are satisfied. In the future development of computer software technology, it is necessary to actively develop the computer technology related to the times, so as to fully reflect the advantages of computer technology itself, so that more industries in China can obtain assistance from computer software technology.

\section{References}

[1] Hu Shengyan. The Application of Computer Software Technology in the Era of Big Data [J]. Computer Programming Skills \& Maintenance, 2018, 23(11):104-105,116.

[2]. Zhao Jianping. Research on the Application of Computer Software Technology in the Era of Big Data [J]. China Venture Capital, 2018,2(4):263.

[3] Liu Xiaozhen, Yang Jing, Suo Xiaoran. Research on the Application of Computer Software Technology in the Era of Big Data [J]. Digitalization User, 2018,24(49):125.

[4] Wang Rongjun. Research on the Current Status and Application of Computer Software Technology [J]. Heilongjiang Science, 2018,9(22):62-63.

[5] Hu Kunsheng. Research on the Current Status and Application of Computer Software Development Technology [J]. Digital Space, 2018,17(11):87.

[6] Wang Ruifen. Research on Computer Software Development Technology [J]. Modern Communication, 2017,14(15):18.

[7] Shi Xiaowen. Research on the Current Status and Application of Computer Software Technology [J]. Science and Informatization, 2018,12(4):42-43.

[8] Zhu Xiaoli. Research on Computer Software Development Technology [J]. Digital 
Communication World, 2017,22(10):208,284.

[9] Hou Jie. Research on the Application of Computer Software Technology in the Era of Big Data [J]. Digital Space, 2017,31(11):34.

[10] Li Xinlu. Research on the Current Status and Application of Computer Software Development Technology in the Era of Big Data [J]. :PC Fan, 2017,9(24):14. 